\title{
MICROSTRUCTURE OF COMMERCIAL PURITY TITANIUM SUBJECTED TO COMPLEX LOADING BY THE KOBO METHOD
}

\begin{abstract}
Observations of refined microstructure of Commercial Purity titanium for applications in biomedical devices has been carried out. Refinement of titanium microstructure has been performed in process with complex strain scheme. Materials investigated in this work were: Commercial Purity titanium grade 2 and grade 4. Samples of as received materials were subjected to plastic deformation in complex loading process of extrusion combined with oscillation twisting (KoBo extrusion). Both types of samples were deformed in single step of extrusion, in temperature of $450{ }^{\circ} \mathrm{C}$, with extrusion ratio 19.14 and 12.25 for grade 2 titanium and grade 4 titanium, respectively. Initial mean grain diameter for both types of materials was approximately $30 \mu \mathrm{m}$. Samples were investigated by means of crystal orientation microscopy. In both cases considerable microstructure refinement has been observed. Microstructures of deformed samples are heterogenous and consist of both elongated and fine equiaxed grains. Elongated grains (lamellae) are separated by High Angle Grain Boundaries and feature internal structure with subgrains and dislocation walls. Grain refinement is stronger in material with higher extrusion ratio and mean grain diameter in this case is equal to $1.48 \mu \mathrm{m}$ compared to $8.07 \mu \mathrm{m}$. in material with lower extrusion ratio. Mean misorientation angle $\left(24^{\circ}\right.$ and $27^{\circ}$ for grade 4 and grade 2 titanium) indicates high fraction of HAGBs in microstructures of KoBo deformed samples. Misorientation fluctuations inside grains have been analyzed and distinct curvature of crystal lattice have been observed. Hardness of samples after plastic deformation increased from 174.6 \pm 3.4 and $234.9 \pm 3.5$ to $205.0 \pm 3.2$ and $251.2 \pm 2.2$ for titanium grade 2 and grade 4 respectively.

Keywords: Commercial Purity Titanium, Plastic deformation, SPD, KoBo, Microstructure, EBSD
\end{abstract}

\section{Introduction}

\subsection{Titanium as a biomedical material}

In recent years titanium has been an increasingly important medical implant material [1]. This is owed to its special properties such as high specific strength, low electric and thermal conductivity and most of all excellent biocompatibility and corrosion resistance. Those last two characteristics are especially important for skeletal substitution or fixture applications, as they allow implant to create strong and long lasting connection with bone tissue, thus allowing for implant to be able to stay in patients system for periods of time as long as 15 years. Titanium grade 5 (Ti6Al4V) is the most widely used titanium alloy for implantation applications. Its mechanical strength is considerably improved over unalloyed (commercial purity - CP) grades, which makes it more suitable for implant production. However, there are strong suggestions, that despite high corrosion resistance of titanium, traces of alloyants aluminum and vanadium can be released into patients system, for instance as debris in friction wear processes [2],[3]. This fact is especially important considering prolonged period of implant functioning. While vanadium cations are known to have cytotoxic response in peri-implant tissues, potentially leading to implant loosening and failure, aluminum cations are considered harmful for their neurotoxicity and connection with Alzheimer disease [4]. Therefore currently, efforts are made to develop titanium based materials without addition of any cytotoxic or neurotoxic elements but with mechanical properties sufficient for bone substitution and, load bearing applications such as in dental implants. One possible attempt to solve that problem is development of nano and ultrafine grained commercial purity titanium.

It has been reported [5] that substantial grain refinement of commercially pure titanium leading to ultra-fine and nanograin microstructure can be achieved by SPD (Severe Plastic Deformation) process. ECAP [5][6] and HE [7][8] has been successfully applied in fabrication of bulk nanostructured titanium. Both methods are leading to considerable improvement in mechanical properties which are comparable or exceeding these of Ti6Al4V alloy. Nanostructuring of titanium have additional advantage in form of improved biocompatibility [9]. Valiev et.al. developed implants based on SPD processed $\mathrm{CP}$ grade 2 titanium, which apart from increased strength are characterized with improved biological response from osteoblast cells thanks to nanostructured metal surface [10]. Both ECAP and HE are however complex processes requiring multiple steps of deformation to accumulate sufficient strain in processed material.

\footnotetext{
* INSTITUTE OF METALLURGY AND MATERIALS SCIENCE POLISH ACADEMY OF SCIENCES, 25 REYMONTA STR., 30-059 KRAKÓW, POLAND

\# Corrensponding author: j.kawalko@imim.pl
} 


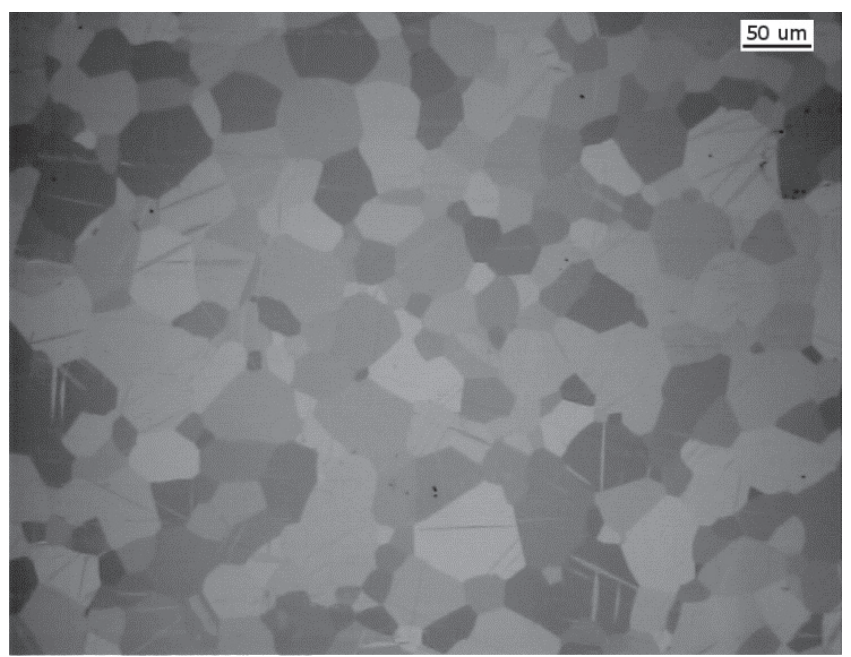

Fig. 1. Typical light micrograph (polarized light) of grade 2 titanium microstructure

TABLE 1

Chemical composition of Commercial Purity titanium grade 2 and grade $4(w t \%)$

\begin{tabular}{|c|c|c|c|c|c|c|}
\hline \hline & \multicolumn{6}{|c|}{ Maximum values (wt\%) } \\
\hline & $\mathbf{O}$ & $\mathbf{N}$ & $\mathbf{C}$ & $\mathbf{H}$ & $\mathbf{F e}$ & $\mathbf{T i}$ \\
\hline grade 2 & 0.25 & 0.03 & 0.08 & 0.015 & 0.3 & balance \\
\hline grade 4 & 0.4 & 0.05 & 0.08 & 0.015 & 0.5 & balance \\
\hline
\end{tabular}

\subsection{Kobo plastic forming technique}

KoBo is a technique for plastic forming of materials that introduces high amounts of strain into material by single step of complex loading. High plastic strain is enabled through decrease of deformation force by destabilization of dislocation structure and activation of heterogeneous visco-plastic flow [11][12]. Destabilization of structure is caused by changes of deformation path during the process which results from cyclic changes in loading scheme. KoBo type extrusion is a combination of classic extrusion with twisting by reversible rotation - oscillation of extrusion die. Oscillation movement of die during extrusion destabilizes materials structure and causes it to deform heterogeneously.
KoBo has been utilized for plastic forming of variety of metals including steels, aluminum alloys and hexagonal metals such as magnesium and zinc [13][14][15]. Both microstructure refinement and improvement in mechanical properties has been reported in processed materials. So far no reports on KoBo processed titanium have been published, however available works suggest that this type of extrusion could be successfully applied for manufacturing of strengthened CP titanium. Additionally high potential for industrial application makes KoBo extrusion good technique for titanium dental implant production.

In this work we are reporting preliminary microstructure observations of KoBo extruded commercial purity titanium.

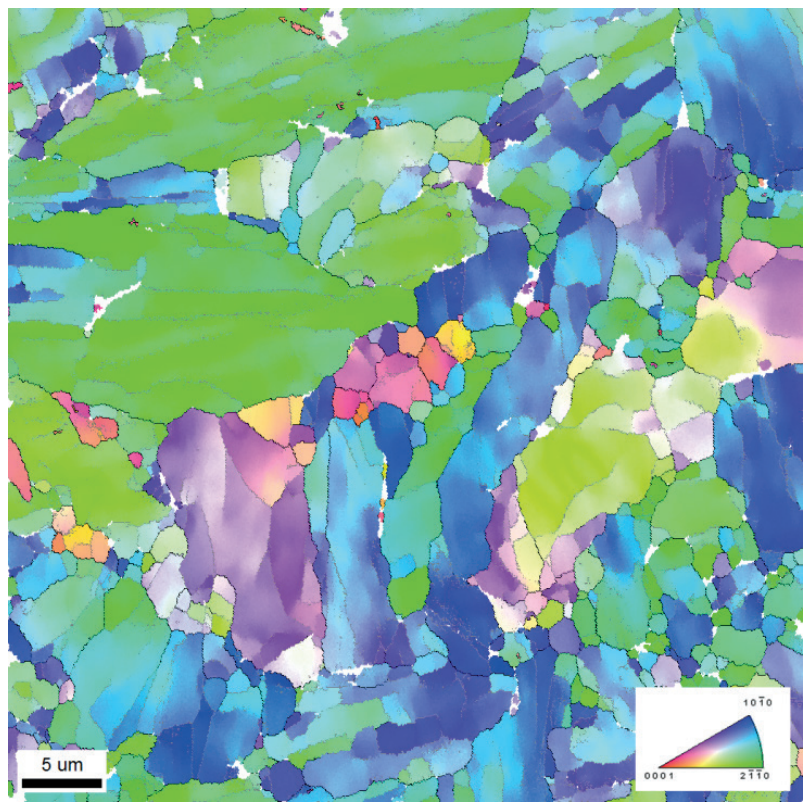

Fig. 3. IPF orientation map of Ti grade 4 sample extruded by KoBo method. HAGB's - black lines, LAGB's - grey lines

\section{Experimental}

For this work commercially available commercially pure titanium grade 2 and grade 4 were used. Typical chemical compositions of titanium grades are presented in table 1. Material was received in form of $35 \mathrm{~mm}$ diameter and $300 \mathrm{~mm}$ length bars. Light micrograph (polarized light)
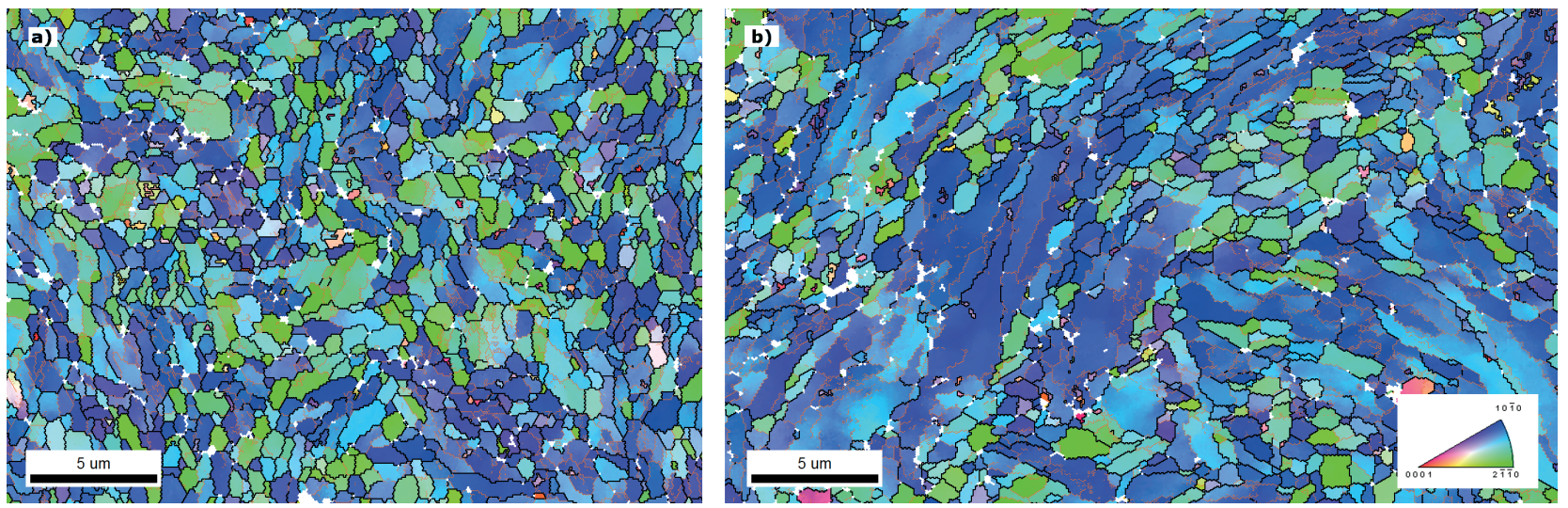

Fig. 2. IPF orientation maps of KoBo extruded Ti grade 2 sample, HAGB's are indicated by black lines, LAGB's - grey lines: a) area with highly fragmented, equiaxed grains b) showing cluster of lamellae 
of grade 2 titanium in as received state is presented on figure 1. Structure of grade 2 and grade 4 titanium in initial state consists of equiaxed grains with mean diameter of 30 microns. Samples for the KoBo extrusion process were prepared in form of $50 \mathrm{~mm}$ long cylinders (35 mm diameter). KoBo extrusion was performed in Faculty of Non-Ferrous Metals at AGH University of Science and Technology. Samples from both grades were preheated to $450{ }^{\circ} \mathrm{C}$ and recipient temperature was set to $400{ }^{\circ} \mathrm{C}$. For extrusion of grade 2 titanium, $8 \mathrm{~mm}$ diameter die was used, and for grade 4 titanium $10 \mathrm{~mm}$ diameter die (true strain e respectively 2.95 and 2.50). True strain was calculated according to following equation: $e=\ln \left(\frac{A_{0}}{A_{e}}\right)$, where $A_{0}$ and $A_{e}$ are cross-sectional areas of rod before and after deformation. Die oscillation frequency and oscillation angle was set to $\mathrm{f}=5 \mathrm{HZ}$ and $+/-6^{\circ}$ respectively for both titanium grades. Extrusion force was 70 $\mathrm{T}$ for grade 2 and $100 \mathrm{~T}$ for grade 4 . The difference in applied die diameter, and in consequence accumulated strain as well as deformation force for grade 2 and grade 4 specimens was dictated by differences in mechanical properties of two titanium grades in initial state. Deformation of grade 4 was not achievable under the same process parameter set as in case of grade 2 titanium.

Crystal orientation microscopy by means of Electron Back Scatter Diffraction technique was performed on FEI Quanta 3D FEG microscope with EDAX TSL OIM ${ }^{\text {TM }}$ software. Samples for EBSD mapping were cut perpendicular to rod axis (transverse sections). Metallographic sample preparation consisted of mechanical grinding with SiC papers down to 4000 grit, followed by polishing step by colloidal silica suspension with $10 \%$ addition of hydrogen peroxide. EBSD mapping was performed at $20 \mathrm{kV}$ with hexagonal grid and step size about $100 \mathrm{~nm}$ for different maps.

Obtained crystal orientation maps were processed by standard grain dilation cleanup routine. Minimum grain size was set to 5 pixels and minimum misorientation angle between grains $5^{\circ}$. Furthermore grains with mean $\mathrm{CI}$ (confidence index) below 0.03 was omitted for grain size analysis. Grain diameter distributions were calculated in TSL OIM Analysis software as diameter of equivalent circles. Distribution of grain diameters and mean grain diameter was calculated with respect to fraction of area occupied by grains with specific diameter.

Mechanical testing was performed by hardness measurement on Zwick/Roell ZHU 250 hardness tester with diamond Vickers pyramid shaped indenter and $50 \mathrm{Kgf}$ load. Hardness of non deformed titanium grade 2 and grade 4 samples was also measured for comparison. Hardness values were averaged from 6 independent measurements from the central areas of all samples.

\section{Results and discusion}

\subsection{Microstructure}

Typical orientation maps of transverse sections grade 4 and grade 2 titanium samples deformed in KoBo with true strain 2.50 and 2.95 respectively are presented on figures 2 and 3. High Angle Grain Boundaries (HAGBs) are indicated as black lines and Low Angle Grain Boundaries (LAGBs) as grey lines. Microstructure of deformed materials is heterogeneous and consists of two main types of grains: coarse elongated lamellae like and fine, equiaxed ones.

In case of grade $4 \mathrm{Ti}$ microstructure is relatively coarse, long axes of grains are reaching lengths of almost $20 \mu \mathrm{m}$ while diameters of fine grains are in the range from $1 \mu \mathrm{m}$ to $5 \mu \mathrm{m}$. Subgrain structure is present mostly in elongated coarse grains with dislocation walls oriented along long axis of grains as well as forming cell structures.

Microstructure of titanium grade 2 (true strain e $=2.95)$ is more refined but highly heterogeneous and similarly to grade 4 consists of mixture of lamellae and equiaxed grains. Lamellae are usually grouped into clusters and separated by HAGBs (fig. 3a). Majority of lamellae are characteristically bent and this curvature is consistent inside a cluster. Clusters and lamellae are however randomly oriented in relation to sample geometry. Most of lamellae are characterized with subgrain structure with considerable amount of dislocation walls oriented parallel to the lamellae long axis. Typically lamellae length is in the range from $5 \mu \mathrm{m}$ to $11 \mu \mathrm{m}$ and thickness from under $1 \mu \mathrm{m}$ to $5 \mu \mathrm{m}$. Remainder grains are finer and closer to equiaxed shape (fig. 3b), however most of them still poses distinct nonunity shape aspect ratio. Diameter of those grains ranges from under $1 \mu \mathrm{m}$ to around $5 \mu \mathrm{m}$. Large fraction of fine grains similarly to lamellae features subgrain structure with dislocation walls. Those grains are also often arranged in bent shapes similar to lamellae cluster shapes. This might suggest that fine grains are in fact products of lamellae fragmentation.

Grain shape aspect ratio distribution is similar for both types of samples, with slightly more equiaxed grains in case of grade 4 titanium.

Overall mean grain diameter for KoBo extruded grade 2 titanium is equal to $1.48 \mu \mathrm{m}$ and $8.07 \mu \mathrm{m}$ for grade 4 . Those values are also presented in table 2 .
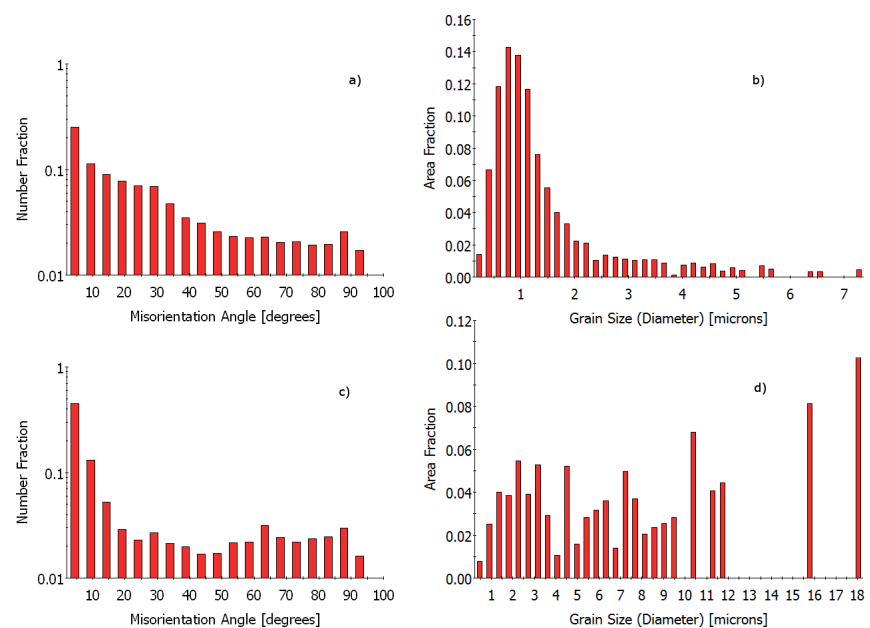

Fig. 4. Misorientation distributions: a),c) and grain size distributions: b),d) of KoBo extruded grade 2: a),b) and grade 4: c),d) titanium 


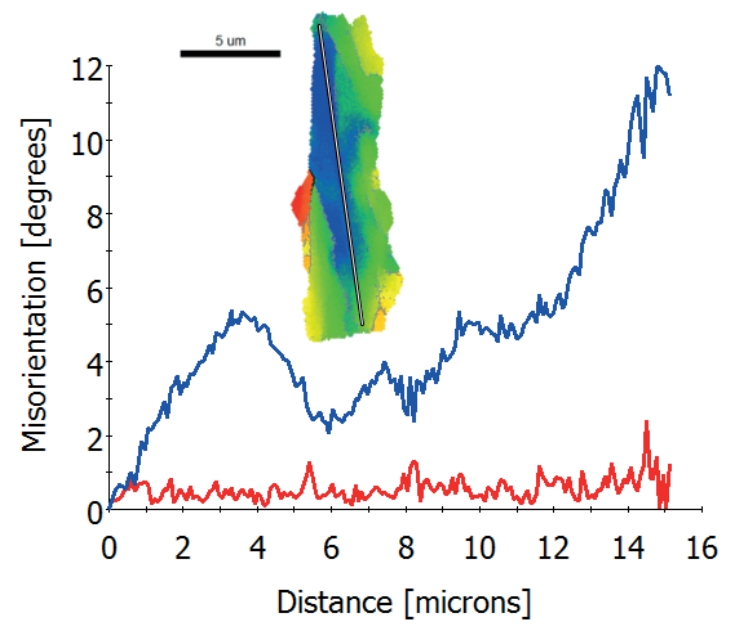

Fig. 5. Misorientation profile measured along grain long axis (white line), blue line - cumulative misorientation, red line - point to point misorientation

In both cases presented microstructures contain fraction of relatively equiaxed (shape aspect ratio $>0.5$ ) and homogeneous (Grain orientation spread $\leq 1$ ) grains, that constitute respectively $9.8 \%$ and $1.9 \%$ structure of grade 2 and grade 4 titanium after KoBo deformation. Those grains are also most refined ones in both types of deformed samples. This type of features suggest that dynamic recrystallization process is involved in deformation and refinement mechanisms during KoBo deformation. Similar microstructures have been found in titanium after ECAP deformation in $400 \mathrm{C}^{\circ}[16]$ and $450 \mathrm{C}^{\circ}$ [17] as well as after Hydrostatic Extrusion [8], where deformation at elevated temperature also leads to dynamic recrystallization and formation of fine globular structure. Presence of orientation gradient in direction of long axis of grain (fig. 5.) is consistent with microstructure observations in titanium after ECAP [19] that can be attributed to continuous dynamic recrystallization (CDRX) process being mechanism responsible for grain refinement. During CDRX subgrains are subject to progressive rotation that gradually increases misorientation leading to development of misorientation gradient from grain centre to edge. Misorientation is increased further by subgrain rotation in areas closer to old grain boundaries and with larger strains, this results in creation of new high angle grain boundaries in those areas [20].

\subsection{Grain size distribution}

Grain size distribution histograms for grade 2 and grade 4 titanium are presented on figures $4 \mathrm{~b}$ ) and $4 d$ ). It can be observed that microstructure of grade $2 \mathrm{Ti}$ after deformation with 2.95 true strain is composed of smaller grains when compared to grade 4 . Distribution for grade 2 is narrower $(0.22$ to $7.28 \mu \mathrm{m}$ as opposed to 0.46 to $18.04 \mu \mathrm{m}$ in grade 4 ) and peaks on histogram are shifted to the left where grain diameter values are concentrated close to main peak at $0.77 \mu \mathrm{m}$, while in case of grade 4 values are more evenly distributed across the histogram.
TABLE 2

Mean values from hardness tests, respective true strain e, and mean grain size after KoBo extrusion

\begin{tabular}{|c|c|c|c|c|}
\hline \hline Material & $\begin{array}{c}\text { Initial } \\
\text { hardness } \\
\text { HV 5 }\end{array}$ & $\begin{array}{c}\text { KoBo } \\
\text { hardness } \\
\text { HV 5 }\end{array}$ & $\begin{array}{c}\text { True } \\
\text { strain e }\end{array}$ & $\begin{array}{c}\text { KoBo } \\
\text { mean } \\
\text { grain } \\
\text { diameter } \\
\boldsymbol{\mu m}\end{array}$ \\
\hline Ti grade 2 & $174.6 \pm 3.4$ & $205.0 \pm 3.2$ & 2.95 & 1.48 \\
\hline Ti grade 4 & $234.9 \pm 3.5$ & $251.2 \pm 2.2$ & 2.50 & 8.07 \\
\hline
\end{tabular}

Despite wide grain diameter distribution in grade 2 (due to elongated grains with lengths over $5 \mu \mathrm{m}$ ), large quantity of observed grains $(47.9 \%)$ have diameter under $1 \mu \mathrm{m}$. In recent study Y. J. Chen et al.[17] investigated grade 2 titanium after 4 and 8 passes of $\mathrm{Bc}$ route ECAP in $450{ }^{\circ} \mathrm{C}$. Chen obtained similarly shaped grain diameter distribution to one presented here for grade 2, however in our work distribution for grade 2 is smoother and grain diameter values are concentrated at left side of histogram. This points to better efficiency of grain refinement observed in our study. However this is not consistent in case of mean grain diameter, despite strong peaks at 5, 7 and 9 micrometers Chen reports smaller mean grain diameter ( 0.59 and 0.56 for 4 and 8 ECAP passes) than observed in our investigations for grade 2 titanium.

\subsection{Misorientation distribution}

Misorientation distributions of KoBo extruded titanium are presented on figures $4 \mathrm{a}$ ) and $4 \mathrm{c}$ ). In cases of both titanium grades relatively small peaks at $28^{\circ}, 63^{\circ}$, and $87^{\circ}$ are visible. Zherebtsov et al. [8] interprets peaks observed in misorientation distribution of Hydrostatically Extruded (HE) grade 2 titanium as twin boundaries such as the $\{101\}\{102\}$ and $\{113\}$ twins with $57^{\circ}, 84.78^{\circ}$ and $86.98^{\circ}$ misorientations. Similarly to Zherebtsov et al. observations, in our study those peaks are less distinct for materials with higher true strain, which suggests that fraction of twin boundaries is decreasing with increasing strain in sample. However, no twins have been observed in microstructures of either KoBo extruded titanium grades (fig. 2 and 3), therefore origin of those peaks will be investigated in detail in future. Moreover, average misorientation angle for both observed types of samples are higher than those observed in HE titanium, and are equal to $24^{\circ}$ and $27^{\circ}$ for grade 4 and grade 2 titanium. This points to overall higher amount of HAGBs in KoBo extruded titanium compared to titanium after HE.

Analysis of small misorientation variation inside elongated grains in both types of extruded samples, implies bending of crystal lattice evident in large portion of these grains. Most of observed elongated grains have cumulative misorientation change in order of around $10^{\circ}$ across grain long axis (fig. 5). Similar effect can be observed in some grains across their short axis, but with smaller cumulative misorientation (up to $5^{\circ}$ ). This amount of crystal lattice bending must be associated with formation of geometrically necessary dislocations (GND's) and dislocation walls in order to accumulate curvature of the lattice. 


\subsection{Mechanical properties}

Results obtained in hardness measurements are presented in table 2. For both grades of titanium extruded by means of KoBo technique increase of hardness has been observed. In case of grade 2 titanium hardness $\mathrm{Hv}$ values increased by $17.4 \%$ from $174.6 \pm 3.4$ to $205.0 \pm 3.2$ after extrusion, while for grade 4 titanium hardness changed by $6.9 \%$ from $234.9 \pm 3.5$ in the initial state to $251.2 \pm 2.2$ for deformed sample.

The increase in $\mathrm{Hv}$ values after KoBo is not as large as found in literature for grade 2 titanium deformed by ECAP or $\mathrm{HE}$ where hardness have been found to increase by up to $66 \%$ [21] and 51\% [22] respectively. It should be noted however that those results were obtained for high strains accumulated during multiple steps of deformation in room temperature (accumulated true strain e 5.04 and 4.6 respectively for ECAP and HE). Lower but significant hardness increase have been observed after single passes of both ECAP and HE (around 18\% and $20 \% \mathrm{Hv}$ increase with accumulated true strain $\mathrm{e} \approx 1.05$ and $\mathrm{e} \approx 0.75$ respectively). Another reference cites hardness value $\mathrm{Hv} 275$ for grade 2 titanium after 8 passes of ECAP route Bc (accumulated strain $\mathrm{e} \approx 8$ ) in temperature $450 \mathrm{Co}$, but does not mention hardness of initial non-deformed material.

Low hardness increase after KoBo extrusion can be attributed to several factors. First one is high deformation temperature which is most likely increased during the deformation through oscillating die. Some softening of deformed titanium have been observed at $450 \mathrm{C}^{\circ}$ due to partial recovery [23], it is likely that additional temperature increase causes quicker dynamic recovery processes during KoBo deformation, preventing accumulation of statistically stored dislocations (SSD) and decreasing hardening rate. At the same time relatively high deformation temperature decreases grain refinement rate due to dynamic recrystallization, therefore grain boundary hardening according to Hall-Petch relation is much less relevant during KoBo process at high temperature. Second factor is the type of deformation during KoBo process which is carried out under conditions of constantly changing deformation path. Material under such conditions is less likely to strain harden due to hindered formation of SSDs and instead becomes highly plastic facilitating visco-plastic flow in layers parallel to extrusion direction. This type of deformation combined with CDRX promotes formation of geometrically necessary boundaries (GNB), that separate areas with relatively low concentration of SSDs, which enables high strain deformation but with low strain hardening of material.

\section{Summary}

Results obtained from microstructural investigation of titanium samples extruded by means of KoBo technique have been presented. The microstructure of deformed samples is significantly refined from initial state and amount of HAGBs is relatively high compared to that observed in HE Ti grade 2 samples. Mean grain diameter observed for grade 2 and grade 4 titanium after KoBo extrusion are equal to $1.48 \mu \mathrm{m}$ and 8.07 $\mu \mathrm{m}$ respectively.

Samples are characterized with heterogeneous microstructure containing both elongated and equiaxial grains with different degree of refinement and subgrain structure. Microstructure of grade 2 titanium after KoBo with true strain 2.95 is more homogenous than in grade 4 samples, grain diameter distribution is narrower and resembles that observed for grade 2 Ti processed by multiple passes of ECAP process. Misorientation fluctuations inside elongated grains suggest presence of GND's accommodating curvature of crystal lattice inside those grains. Characteristic misorientation gradients inside larger grains suggests that CDRX is mechanism responsible for grain refinement during KoBo extrusion.

\section{Acknowledgments}

This work was co-financed by the European Union from resources of the European Social Fund (Project No.POKL.04.01.00-00-004/10) and supported by grant from Polish National Scientific Center (NCN):2011/03/B/ ST8/06120.

\section{REFERENCES}

[1] A. Palmquist, O. M. Omar, M. Esposito, J. Lausmaa, P. Thomsen, J. R. Soc. Interface 7, 515 (2010)

[2] D. Cadosch, E. Chan, O.P. Gautschi, L. Filgueira: J. Biomed. Mater. Res. A 91, 1252 (2009)

[3] Y. Okazaki, S. Rao, Y. Ito, T. Tateishi, Biomaterials;19, 1197 (1998)

[4] A. Hernández-Sánchez, P. Tejada-González, M. ArtetaJiménez, Eur. J. Clin. Nutr. 2013.

[5] YT. Zhu, JY. Huang, J. Gubicza, T. Ungár, Y.M. Wang, E. Ma, R.Z. Valiev, J. Mater. Res. 18(8), 1908 (2003)

[6] A.V. Sergueeva, V.V. Stolyarov, R.Z. Valiev, A.K. Mukherjee, Scr. Mater. 45(7), 747 (2001)

[7] W. Pachla, M. Kulczyk, M. Sus-Ryszkowska, A. Mazur, K.J. Kurzydlowski, J. Mater. Process. Technol. 205, 173 (2008)

[8] S. Zherebtsov, W. Lojkowski, A. Mazur, G. Salishchev, Mater. Sci. Eng., A 527, 5596 (2010)

[9] Y. Estrin, C. Kasper, S. Diederichs, R. Lapovok, J. Biomed. Mater. Res. A 90, 1239 (2009)

[10] R.Z. Valiev, I.P. Semenova, E. Jakushina, V.V. Latysh, H. Rack, T.C. Lowe, J. Petruželka, L. Dluhoš, D. Hrušák, J. Sochová, Mater. Sci. Forum; PART 1:49-54, 584 (2008)

[11] A. Korbel, W. Bochniak, European Patent No. 0711210, U.S. Patent No. 573959.

[12] A. Korbel, W. Bochniak, P. Ostachowski, L. Blaz, Metall. Mater. Trans. A, 42A, 2881 (2011)

[13] K. Pieła, L. Błaż, M. Jaskowski, Arch. Metal. Mater. 58, 683 (2013)

[14] A. Korbel, J. Pospiech, W. Bochniak, A. Tarasek, P. Ostachowski, J. Bonarski, Int. J. Mat. Res. 102, 464 (2011)

[15] K. Sztwiertnia, J. Kawałko, M Bieda, K. Berent, Arch. Metal. Mater. 58, 157 (2013)

[16] L. Wang, Y. C. Wang, A. P. Zhilyaev, A. V. Korznikov, Shu Kui Li, E. Korznikova, T. G. Langdon, Scr. Mater. 77, 33 (2014)

[17] Y.J. Chen, Y.J. Li, J.C. Walmsley, S. Dumoulin, S.S. Gireesh, S. Armada, P.C. Skaret, H.J. Roven, Scr. Mater., 64, 904 (2011)

[18] C. Hyun, J. Lee, H. Kim, Res. Chem. Intermediat., 36, 629 
[21] X. Zhao, X. Yang, X. Liu, X. Wang, T.G. Langdon, Mat. Sci. Eng., A, 527, 6335 (2010)

[19] Y.J. Chen,Y.J. Li, J.C. Walmsley, S. Dumoulin, P.C. Skaret, H.J. Roven, Mat. Sci. Eng., A 527, 789 (2010)

[20] F.J. Humphreys, M. Hatherly, Recrystallization and Related Annealing Phenomena 2nd ed, Pergamon, Oxford, United Kingdom (2004) pp. 438
[22] K. Topolski, W. Pachla, H. Garbacz, J. Mater. Sci. 48, 4543 (2013)

[23] R.J. Contieri, Zanotello, R. Caram, Mat. Sci. Eng., A 527, 3994 (2010)

Received: 10 March 2015 